\title{
UrbanSAT- Urban System Analysis Tool : For delivering urban water balancing and reporting
}

\author{
$\underline{\text { Amgad Elmahdi }}_{2}{ }_{2}$ Chandrika Jayatilaka ${ }^{\text {a }}$ and David King ${ }^{a}$ \\ ${ }^{a}$ Urban Water Balance Unit, Water Resources Assessment Section, Climate and Water Division, Bureau of \\ Meteorology, Australia.Email: A.Elmahdi@bom.gov.au
}

\begin{abstract}
The UrbanSAT (Urban System Analysis Tool), developed at the Bureau of Meteorology, is an innovative approach to analysing and reporting on the urban water cycle and links to regional water resources using data being delivered to the Bureau under the Water Act 2007. The UrbanSAT is a structured data capture and reporting tool which focuses on the movement of water through urban water distribution systems. It considers directly abstracted water in 'unconnected' areas and alternative water supplies within 'connected areas' via rainwater tanks, groundwater bore, surface water diversions or use from farm dams. Inclusion of this level of detail is, however, contingent upon data availability and estimation methods. Around Australia, annual reporting on urban water use generally focuses on the individual performance of water utilities, with respect to the service(s) they provide for water supply and wastewater collection. UrbanSAT, however, provides a nationally consistent urban water balance, analysis and presentation of water movements and use in urban centres on a whole of system basis. This is particularly useful where there are multiple utilities or suppliers operating throughout one connected system, which occurs in many of Australia's capital cities. For each urban centre considered, UrbanSAT provides information relating to the volume and source of water taken (i.e. when the urban water entitlement is fulfilled), consumption and the volume and location of water returned. The UrbanSAT accounts for the total volume of water taken, supplied and discharged with respect to the major elements of urban water distribution systems (urban water supply system, urban wastewater system, urban recycled water supply system, irrigation supply system). Deliverables of UrbanSAT are an important part of the Bureau's National Water Account 2010. The application of the UrbanSAT includes; a set of schematics illustrating the hierarchy of flows within the system, a data capture tool, urban water balance figure, series of tables summarising water flows and supporting documentation. The UrbanSAT data capture tool consists of approximately 50 system generic transactions, capturing inflows, outflows and flows between the four components of the water distribution system; the urban water supply system (potable and non-potable), wastewater system, recycled water supply system and irrigation water supply system. The Adelaide urban water system is considered as a case study in this paper with its application discussed and an extract of outcomes presented.
\end{abstract}

Keywords: UrbanSAT, system analysis, Water balance, urban system 


\section{INTRODUCTION}

Water is a key resource to sustain human life. Equitable allocation of water resources is a growing challenge due to the increasing demand for water and the competing values placed on its use. Availability of affordable and good quality water is critical for the Australian environment, the economy, for industry and food production, and for the community's health and lifestyle. The main challenge for Australia is to balance a highly variable water supply among the demands from different users and balance its triple bottom line values. One of the main constraints to decision making processes in Australia is the lack of comprehensive information on the availability and characteristics (trend and variability) of both water quantity and quality.

Under the Commonwealth Water Act (2007), the Bureau of Meteorology (the Bureau) has the responsibility for compiling and delivering comprehensive water information across Australia. This includes providing regular reports on the status of the nation's water resources and patterns of water use. To fulfil this function the Bureau will each year publish national water resources assessments that profile the status of, and variability in, the quantity, quality and use of water across Australia.

The successful release of the first National Water Account (NWA - BoM, 2010) is one of the highest priorities for the Climate and Water Division, and Water Information Service Branch, over the last 12 months. One of the main focuses of the NWA was the representation of total water resource, water taken and used for urban centres around Australia, particularly the capital cities. The NWA is underpinned by detailed water balance assessments (both rural and urban), one of the core functions of the Water Resource Assessment (WRA) section within the Bureau. Water balance assessments also serve a range of other products to be produced by the WRA section, including Australian Water Resources Assessment 2010 (AWRA10 - BoM, 2011a), and associated products.

For the purpose of the NWA, a water balance is taken to mean a "comprehensive evaluation of the inputs, outputs and change in storage within a physical water reporting entity, including precipitation and evapotranspiration, as well as other fluxes of water through the terrestrial environment." The Water Accounting Statements contained within NWA 2010 (BoM, 2011b) are structured in accordance with the Exposure Draft of Australian Water Accounting Standard 1 (WASB, 2010). The Water Accounting Statements comprise of (1) Statement of Water Assets and Water Liabilities; (2) Statement of Changes in Water Assets and Water Liabilities; and (3) Statement of Physical Flows. These statements are designed for application across all entities, irrespective of the dominant characteristics of the region (such as land use, water features, or administrative arrangements). That is, these Water Accounting Statements should be comparable across all sub-accounts, regardless of whether the entity has an urban or rural focus.

The Pilot NWA (BoM, 2010) presented sub-accounts based on regional water balances, defined by the hydrological boundary that best represented the reporting entity. Additionally, the Chart of Accounts used for the Pilot NWA stopped at the point where an entitlement was taken, and did not account for actual usage of the water and water movements. The Pilot NWA did not adequately present the information required to show water movements in urban centres. The feedback received from the stakeholders revealed the need to expand the representation of the urban water systems beyond the point of bulk water supply extraction.

In response to the above mentioned issues to consider and expand urban reporting regions, the UrbanSAT (Urban System Analysis Tool) concept was developed at the Bureau for inclusion in NWA 2010 (BoM, 2011b) for reporting on six major urban centres around Australia. The UrbanSAT is an innovative approach to analysing and reporting on the urban water cycle and links to regional water resources using data being delivered to the Bureau under the Water Act 2007. Current annual reporting on Australian urban water use focuses on water utilities' individual performance indicators, with respect to the service(s) they provide for water supply and wastewater collection. With the UrbanSAT, the NWA is providing a unique view of water movements and usage in urban centres, by providing information on a whole of system basis and system analysis. This is particularly useful where multiple utilities/suppliers operate throughout one connected system or reporting region, which occurs in many of Australia's capital cities. Also, UrbanSAT will provide answers to the following key and core questions regarding urban centres: How much water is taken by urban centres and from which sources (external and internal)? How much water is returned, and what is its quality?

The purpose of UrbanSAT is to enhance the representation of urban dominated regions in a water accounting report presented in the NWA and to provide users with greater detail of urban water resources management than would appear in the three Water Accounting Statements alone. This is, in part, in response to stakeholder feedback on the need to expand representation of urban water systems beyond the point of bulk water supply extraction. It is also in response to the greater emphasis on urban reporting proposed in the Pilot NWA. This paper details the UrbanSAT concept, its development and a case study application considering the Adelaide region. 


\section{URBANSAT AIM AND CONCEPT}

The UrbanSAT aims to address the following series of questions that are specific to urban water systems:

- What is the appropriate spatial dimension to use as a reporting boundary in an urban context? (examples include: geographical area, water supply system infrastructure, wastewater collection infrastructure, system operator boundary, legal responsibility to manage boundary)

- Which urban water system components need to be represented in the NWA, and at what nested level (simple, intermediate and detailed)?

- What are the typical data sources and/or analysis needs to populate each of the urban water system components that are to be represented in the National Water Account?

The overarching concept of the UrbanSAT is 'progressive reporting that builds system understanding'. The idea behind this concept is that through producing reporting products, such as the NWA, and progressively building more detail and information into them, we will simultaneously build a greater understanding of the systems on which we are trying to report. This is in contrast to a traditional research/exploratory approach, whereby the understanding of a system precedes the production of a report. As a component of the NWA 2010 (BoM, 2011b) Capture Tool, UrbanSAT drills into greater detail about the movement of water through urban water systems (covering supply-use-discharge). Figure 1 shows diagrammatically how UrbanSAT, which corresponds to the Water Distribution System Store block, interfaces with the regional water balance; these flux terms are also reflected in tabular form within the NWA 2010 Capture Tool.

The NWA 2010 Capture Tool covers the complete set of stores contained within the water report entity (Figure 1). UrbanSAT is a structured data capture and reporting tool which focuses on the movement of water through urban water systems specifically. UrbanSAT has been designed as a scalable solution for reporting urban water within a water account (Figure 2). While initial focus will be upon the 'connected' water and wastewater infrastructure, there is scope to expand coverage within UrbanSAT to 'unconnected' peri-urban areas, and decentralised water use within connected urban areas, such as that associated with rainwater tanks and domestic groundwater bores. Inclusion of this level of detail is, however, contingent upon data availability. In the NWA 2010, attention was focused on the connected urban areas.

\section{URBANSAT AND REGIONAL WATER BALANCE}

System analysis approach has been used to identify the components of urban water systems that are essential for reporting at three nested levels simple, intermediate and detailed levels (defined below). However, simple, intermediate and detailed levels may not be easily divided between wholesaler and retailer etc, as the complexity and interconnects of the urban system components and some components presented at simple or intermediate levels involve building up from detailed level.

1. Simple - the overall balance for the urban system at a wholesale level including imports and exports, and the (inferred) change in storage i.e. raw water in, and discharge out, of the system;

2. Intermediate - the bulk water movements within the urban system (wholesaler);

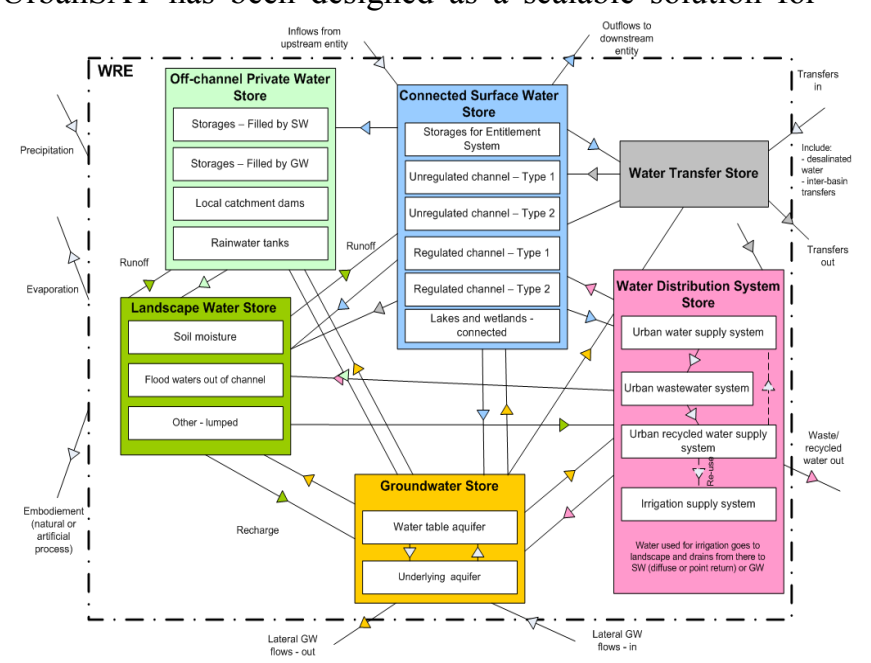

Figure 1. Physical water stores within a water report entity

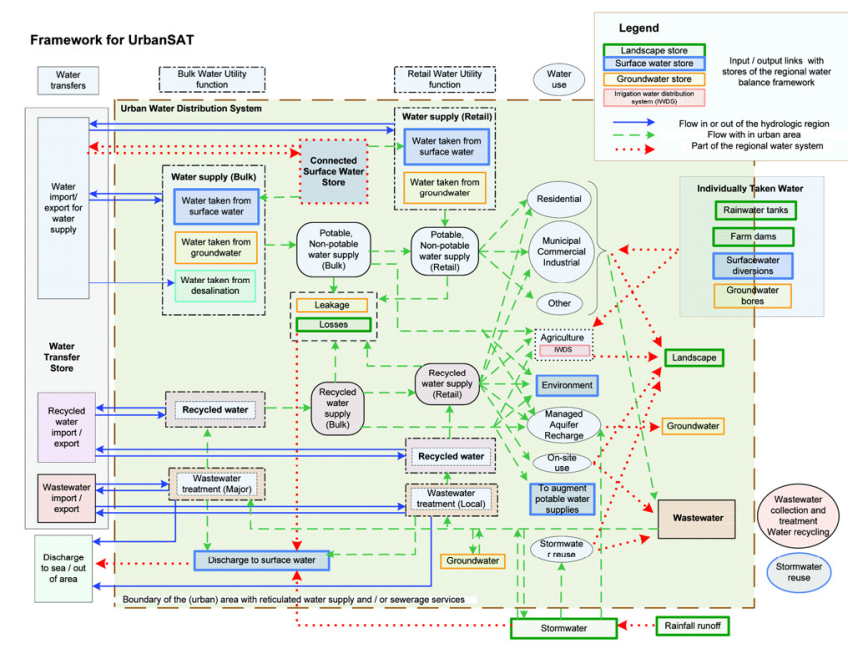

Figure 2. UrbanSAT framework 
3. Detailed - the breakdown of these bulk water movements into water usage sectors as provided via retail water utilities (e.g. residential, commercial, industrial, municipal, unaccounted for water, and other), and tracks local wastewater recycling, local transfers of water, interactions between urban water infrastructure and groundwater, etc.

Around Australia, annual reporting on urban water generally focuses on the individual performance of water utilities, with respect to the service(s) they provide for water supply and wastewater collection. UrbanSAT, however, provides a nationally consistent urban water balance, analysis and presentation of water movements and use in urban centres on a whole of system basis using urban water balance principles within regional water sharing framework (Figure 3). This is particularly useful where there are multiple utilities or suppliers operating throughout one connected system, which occurs in many of Australia's cities. For each urban centre considered, UrbanSAT provides information relating to the volume, water type and source of water taken (i.e. when the urban water entitlement is fulfilled), consumption and the volume and location of water returned. The UrbanSAT accounts for the total volume of water taken, supplied and discharged with respect to the major elements of urban water distribution systems, consisting of urban water supply system, urban wastewater system, urban recycled water supply system, irrigation supply system. Deliverables of UrbanSAT are an important part of the Bureau's NWA 2010.

The UrbanSAT is able to represent the close urban water cycle that can support integrated urban water system management. It links wholesaler to retailer to usage to generated wastewater to recycle water. It provides transparency on the bulk, retail potable water supply and sewerage services and local and regional water cycles and the relevant linkages. It has helped to consolidate urban water definitions with other agencies (National Water Commission, Water Services Association of Australia, jurisdictional, etc) as following:

- Potable water is water that intended for use as a drinking water supply and should materially meets the Australian Drinking Water Guidelines 2004, or equivalent;

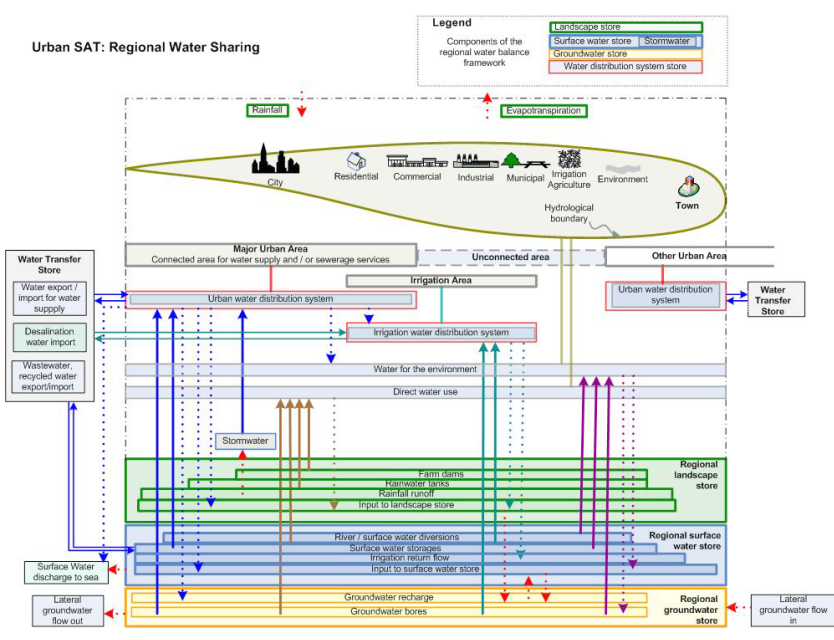

Figure 3. UrbanSAT concept and Regional Water Sharing

- Non-potable water is water that is not intended for use as a drinking water supply;

- Raw water is water that is un-treated water;

- Urban stormwater is water within the urban stormwater drainage system;

- $\quad$ Recycled water is treated sewage effluent, including sewer mining. May be potable or non-potable. Excludes urban stormwater reuse;

- Urban stormwater reuse is treated urban stormwater. May be potable or non-potable;

- Desalination water the volume of water sourced from desalination processes and not confined to marine desalination;

- Marine desalination water the volume of water sourced from marine water and exclude volume sourced from groundwater and surface water.

UrbanSAT has been applied for six major urban centres (Melbourne, Sydney, Canberra, Perth, Adelaide and South East Queensland) in the first NWA (BoM, 2011b). The application of the UrbanSAT includes; a set of schematics illustrating the hierarchy of flows within the system, a data capture tool, urban water balance figure, series of tables summarising water flows and supporting documentation. The urban water balance figure and tables summarise the inflows, outflows, and changes in each water systems (supply, wastewater, recycled, irrigation, etc) by water sources (surface, groundwater, desalination, etc) and water type (potable, non-potable, recycled, etc). The following section briefly presents an application of the UrbanSAT considering the Adelaide system. 


\section{APPLICATION}

Figure 4 shows the simple (Figure 4a) and detailed (Figure 4a) level of water flow hierarchy for the Adelaide urban water supply system. These schematics helped develop understanding and document the transactions within each system. The NWA reporting region for Adelaide is shown in Figure 4a. This area was based on significant hydrological and natural resource management boundaries and is used as the physical extents of the Adelaide UrbanSAT. The detailed schematic (Figure 4b), records the type and use of specific flows of the system, the owner of the flow (if multiple utility system) and the relevant UrbanSAT transaction.

The UrbanSAT capture tool listed approximately 50 system generic transactions capturing the inflows, outflows and flows between the four components of the water distribution system; the urban water supply system (potable and nonpotable), wastewater system, recycled water supply system and irrigation water supply system. The UrbanSAT capture tools were completed in close collaboration with relevant reporting agencies, including water authorities and utilities. The required data was collected via a variety of methods including measured and/or calculated flows; meter readings, analysis of billing records and GIS computations. Input into the NWA sub-accounts included multiple stages from data collection, compilation and balance. The UrbanSAT components of the NWA 2010 produced approximately 200 separate flows and supporting notes for describing the Urban Water systems and derivation of water balances for six urban centres. Notes disclosing data sources, methodology, accuracy, limitation and caveats, amongst other information were also produced.

The quantity of the captured data and documentation depended on the availability and quality of data, number of system components and number of agencies and utilities of a system. For a single agency system, such as Adelaide, 23 individual flow components were identified, whereas for a multiple agency managed system like Melbourne more than 80 flows were identified, analysed, balanced and documented.

The UrbanSAT water balance summary figure shows the inflows and outflows of the system and the flows between the four components of the water distribution systems. Figure 5 shows a summary of the urban water balance figure for the water distribution system in Adelaide, displaying quantified flows in megalitres (ML), flows where sufficient data was unavailable to quantify (NDA - No Data Available) and flows that do not exist in the system (NA - Not Applicable). Some flows shown in Figure 5 are combined for simplicity, such as the diversion to sea and surface water, while further information was added to the balance figure such as the total water use. Flows in a water distribution system are not limited to those given in Figure 5.

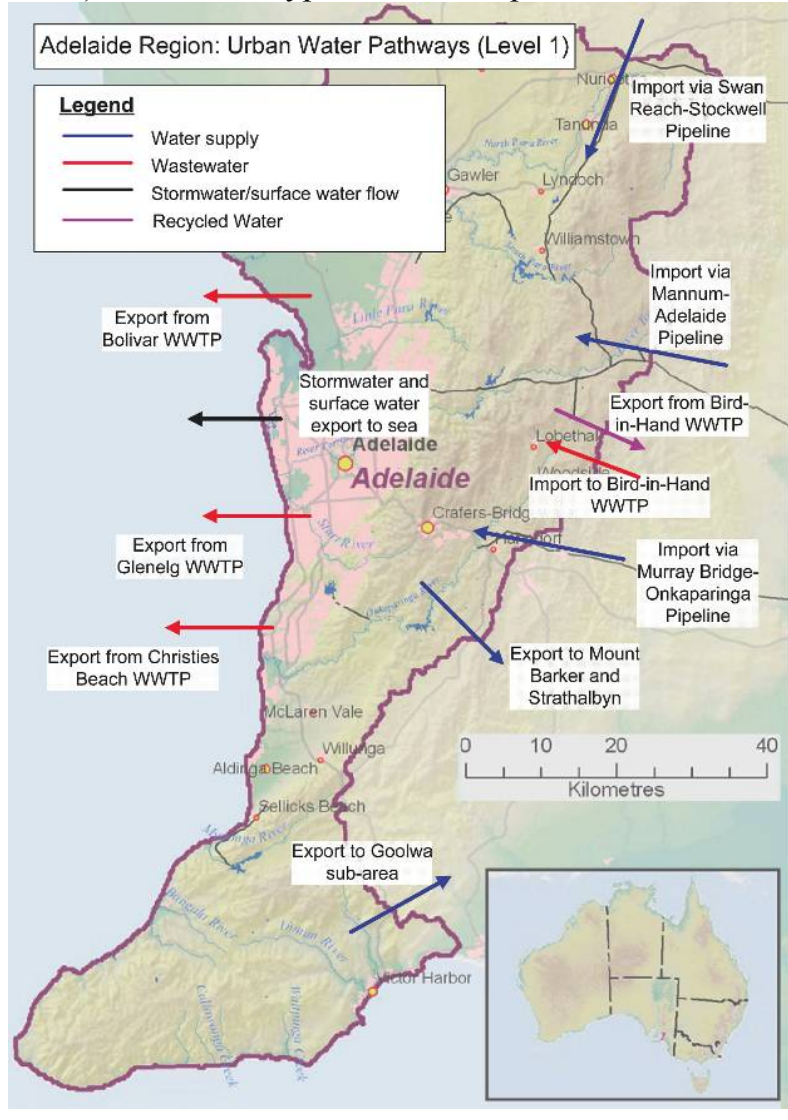

Figure 4a. Simple level flows for the Adelaide system, showing flows at a wholesale level

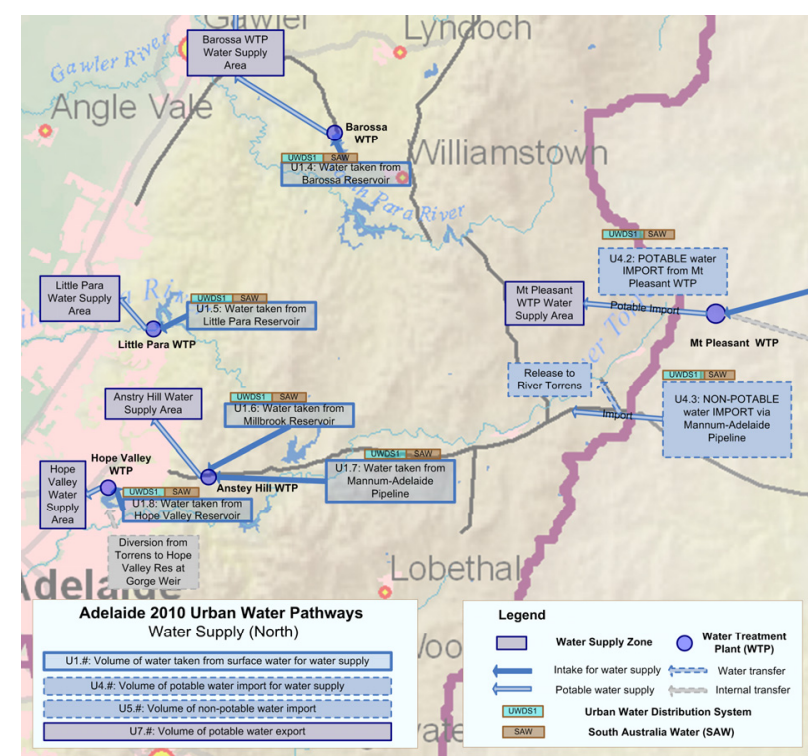

Figure 4b. Detailed level flows (partial) for the Adelaide system, showing flows at a water utility level 


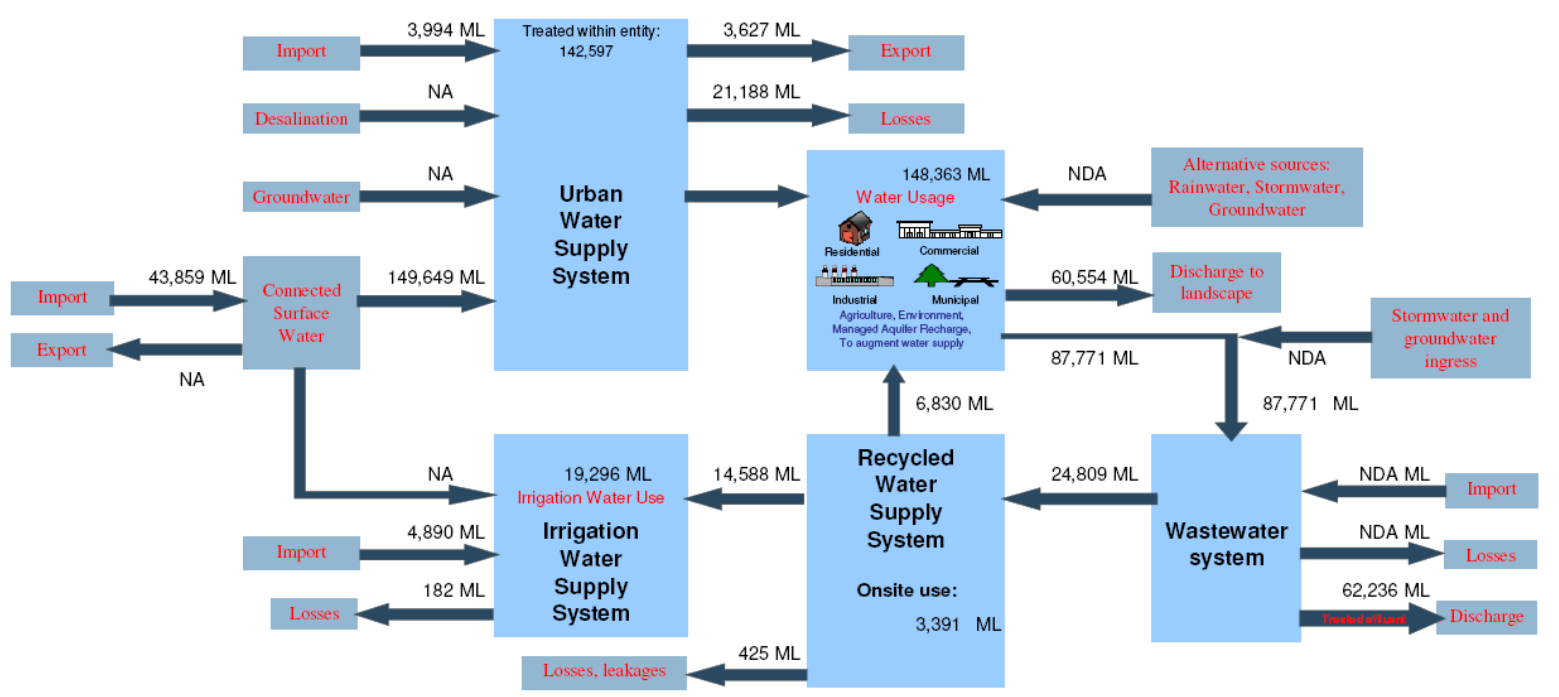

Figure 5. UrbanSAT Water Balance Figure

Several tables and documentation supporting each flow were produced for each system. The tables and documentation for the Adelaide system are not provided here for brevity but can be viewed at the National Water Account Online 2010 website: http://www.bom.gov.au/water/nwa/2010.

Four components of the water distribution system in Adelaide are shown in Figure along with a separate block representing water use. Inflows into the urban water supply system include non-potable surface water, potable and non-potable water import, and water taken from desalination and groundwater sources. The nonpotable water import is for water supply in Adelaide, sourced from the River Murray via the Murray BridgeOnkaparinga pipeline and Mannum-Adelaide pipeline. Potable water is imported via the Swan ReachStockwell pipeline and from the Mt. Pleasant water treatment plant. Outflows from the urban water supply system includes supply for usage, export and non-revenue-water including leakage and pipe bursts.

The water use component in Figure 5 shows water is sourced via the urban water supply system and recycled water supply system as well as alternative sources: groundwater, stormwater and rainwater tanks. Water use is summarised in Table 1. Water is discharged from this component to sewer, landscape or to groundwater.

Wastewater system inflows include flows from water use through sewer, stormwater and groundwater ingress into the sewer system and untreated wastewater imports. Outflows consist of exports, losses, and treated effluent discharges to sea, surface water, landscape, and to recycled water supply system component.

The recycled water supply system has flows to the urban water use component and to the irrigation supply system as well as onsite use, leakages and losses. Adelaide's urban recycled water use includes municipal use on gardens and sports fields, and at Mawson Lakes for landscape use and toilet flushing; all given as the flow to the water use component. Recycled water is also supplied to large irrigation systems, such as the Northern Adelaide Irrigation Scheme, given as a flow to irrigation supply system.

Water is also imported and transferred from connected surface water for irrigation water supply. Evaporation and seepage loss from the irrigation system are also shown in Figure 5.

Figure 5 shows that a number of components in the Adelaide system remained unknown, including alternative water sources such as rainwater tanks, individual groundwater pumping and stormwater reuse. These were identified but not considered in this UrbanSAT due to data limitations. They will be included in the future depending on sufficient data and/or verified estimation techniques.

Table 1. Adelaide water consumption in $2009-10$ by sectors and water type.

\begin{tabular}{|l|l|}
\hline Water usage & Volume (ML) \\
\hline Residential - potable water & 85,957 \\
\hline Residential - non-potable water & NDA \\
\hline $\begin{array}{l}\text { Commercial, industrial, municipal - } \\
\text { potable water }\end{array}$ & 24,773 \\
\hline $\begin{array}{l}\text { Commercial, industrial, municipal - } \\
\text { non-potable water }\end{array}$ & NDA \\
\hline $\begin{array}{l}\text { Other uses including agriculture and } \\
\text { non-revenue water - potable water }\end{array}$ & 30,803 \\
\hline $\begin{array}{l}\text { Other uses including agriculture and } \\
\text { non-revenue water - non-potable water }\end{array}$ & NDA \\
\hline Environment - potable water & NA \\
\hline Environment - non-potable water & NA \\
\hline $\begin{array}{l}\text { Residential, commercial, industrial, } \\
\text { municipal and other - recycled water }\end{array}$ & 6,830 \\
\hline Total water use & $\mathbf{1 4 8 , 3 6 3}$ \\
\hline
\end{tabular}


UrbanSAT analysis allows water balance evaluations which indicate the difference between inflow and outflows of each component of the water distribution system. Major flows of the system were captured however a number of components may not balance due to lack of data such as from private diverters and users, or were not considered, such as the alternative water sources. Alternative water sources were not available to quantify, however can contribute to wastewater collected from the region (e.g. use of water from rainwater tanks for toilet flushing) which causes a cascade of components that may not balance. Estimation of such components will be included in future UrbanSAT applications.

The example shown in this section and the other five UrbanSAT analyses developed for the National Water Account 2010 can be viewed at http://www.bom.gov.au/water/nwa/2010.

\section{CONCLUSION}

The UrbanSAT (Urban System Analysis Tool) concept provides a nationally consistent and systematic approach to the capture, analysis and presentation of data representing urban water flows of the water distribution system. UrbanSAT considers intake from the regional water stores of surface, groundwater and landscape and return of flows to those regional water stores, as well as imports into and outflow from the geographic region. Water flow through and between system components on a whole of system basis including (1) intake of water to the water supply system and supply of water to different use categories, (2) wastewater collection, treatment and discharge, (3) recycled water production and a (3) supplies and use via the irrigation water supply system. UrbanSAT also considers water use categories and alternative water sources in the connected areas. It highlights the current data deficiencies, provides a basis for evaluating the urban water balances and relative importance various system components.

UrbanSAT can represent the urban water cycle with integrated urban water system management, linking wholesaler to retailer to usage to generated wastewater to recycle water. The UrbanSAT concept provides a transparent representation of the urban water cycle, considering bulk, retail water supply and sewerage services, local and regional water cycles and the relevant linkages. The development and application of the UrbanSAT has helped to consolidate urban water definitions with other agencies creating Australia wide standard urban water definitions based on their practical use and applicability.

Furthermore, UrbanSAT provides a systematic means to derive line items required to provide input on urban regional sub-accounts of the National Water Account facilitating evaluation of the water balance of each component of the water distribution system. UrbanSAT provided vital input to the preparation of the first National Water Account published by BoM (2011b) as demonstrated by its application in the Adelaide region included in this paper. UrbanSAT will be developed further to refine input to NWA, Australia Water Resources Assessment and detailed urban water reporting by BoM.

The UrbanSAT has been successfully applied to the Adelaide, Canberra, Melbourne, Perth, South East Queensland and Sydney urban water supply systems. This paper provides case study of applying the UrbanSAT to the Adelaide urban water system. This case study given in this paper and the UrbanSAT applications to the other five urban centres presented in the NWA 2010, shows that the system generic framework and concept of the UrbanSAT can be used to present clear yet detailed analysis, balance and presentation of urban water use, specific to any urban water system.

\section{ACKNOWLEDGMENTS}

The authors would like to express their appreciation to the collegues in the Water Information Sevices Branch at the Bureau of Meteorology and to staff at SA Water for their valuable contribution to the UrbanSAT and National Water Account 2010.

\section{REFERENCES}

Bureau of Meteorology (BoM), (2010), Pilot National Water Account, Commonwealth of Australia, available: http://www.bom.gov.au/water/nwa/document/Pilot_NWA.pdf.

Water Accounting Standards Board (WASB), (2010), Exposure draft of australian water accounting standard 1: Preparation and presentation of general purpose water accounting reports, Commonwealth of Australia, available: www.bom.gov.au/water/wasb.

Bureau of Meteorology (BoM), (2011a), Australia Water Resources Assessment 2010 (AWRA10), Commonwealth of Australia, in press.

Bureau of Meteorology (BoM), (2011), National Water Account 2010, Commonwealth of Australia, available: http://www.bom.gov.au/water/nwa/2010. 